\title{
TINGKAT KEPUASAN PASIEN PENGGUNA GIGI TIRUAN LEPASAN TERHADAP PELAYANAN KESEHATAN GIGI DAN MULUT DI RUMAH SAKIT KHUSUS DAERAH PROVINSI SULAWESI SELATAN
}

\author{
Nurhaeni, Syamsuddin Abubakar
}

\begin{abstract}
ABSTRAK
Studi ini meneliti tentang tingkat kepuasan pasien pengguna gigi tiruan lepasan terhadap pelayanan kesehatan gigi dan mulut di Rumah Sakit Khusus Daerah Gigi dan Mulut Provinsi Sulawesi Selatan, Jumlah sampel dalam penelitian ini adalah 30 responden. Penelitian ini bertujuan untuk mengetahui tingkat kepuasan pasien pengguna gigi tiruan lepasan terhadap pelayanan kesehatan gigi dan mulut di Rumah Sakit Khusus Daerah Gigi dan Mulut Provinsi Sulawesi Selatan. Pengambilan sampel dilakukan dengan metode accidental sampling. dimana siapa saja yang secara kebetulan/accidentalbertemu dengan peneliti dapat digunakan sebagai sampel. Jenis penelitian ini adalah observasional deskriptif dengan pendekatan cross sectional, dengan menggambarkan tingkat kepuasan pasien terhadap pelayanan kesehatan gigi dan mulut dengan melihat berbagai variabel yang akan diteliti diantaranya adalah kompetensi teknis (jaminan), efektifitas layanan kesehatan, efesiensi pelayanan kesehatan (daya tanggap), kenyamanan (tampilan fisik), hubungan antar manusia (empati). Dari hasil penelitian yang dilaksanakan di ruangan prosto dapat dilihat bahwa tingkat kepuasan pasien terhadap pelayanan di Rumah Sakit Khusus Daerah Gigi dan Mulut Provinsi Sulawesi Selatan rata-rata sangat puas.
\end{abstract}

Kata kunci: Kepuasan, jaminan, efektifitas, efesiensi, kenyamanan, empati.

\section{PENDAHULUAN}

Gigi merupakan salah satu organ tubuh yang mempunyai peran penting pada tubuh manusia di antaranya berfungsi untuk mengunyah, berbicara, dan dalam berpenampilan. Gigi yang sehat jika tidak dirawat dengan baik akan menyebabkan timbulnya masalah, antara lain gigi tanggal. Setiap individu idealnya mempertahankan gigi permanen sepanjang hidup, namun demikian gigi dapat lepas atau perlu dicabut dengan berbagai alasan

Kehilangan gigi antara lain dapat disebabkan oleh karies, penyakit periodontal dan trauma. Kehilangan gigi dapat berpengaruh terhadap aktivitas sosial. Hal ini selaras dengan pendapat McGrath dan Bedi yang dikutip oleh Emini bahwa kehilangan gigi dapat mempengaruhi keadaan fisik seperti penampilan estetik, terganggunya sistem mastikasi dan mempengaruhi kenyamanan bicara. Hasil penelitian Wong menemukan bahwa kehilangan gigi geligi dapat mempengaruhi keadaan fisik dan psikologis, seperti kurangnya percaya diri dan keterbatasan aktifitas sosial (Jatuadomi dkk, 2016). Gigi mempunyai banyak peran pada seseorang, Hilangnya gigi dari mulut seseorang akan mengakibatkan perubahanperubahan anatomis, fisiologis maupun fungsional, bahkan tidak jarang pula menyebabkan trauma psikologis. Keadaan ini berdampak pula pada meningkatnya kebutuhan akan gigi tiruan (Sri Wahyuni \& Sefy Ayu Mandanie, 2017), (Djoko, 2008 dalam Chandra dkk, 2014)

Kesehatan gigi dan mulut
merupakan bagian yang esensial dan
integral dari kesehatan secara umum.
Seorang individu dikatakan sehat apabila
secara fisik, mental, spiritual maupun sosial
memungkinkan untuk hidup produktif secara
sosial maupun ekonomis sebagaimana
pengertian sehat dalam Undang-undang
Kesehatan No. 36 Tahun 2009. Kesehatan
gigi dan mulut yang baik dibutuhkan dalam


berbagai aspek kehidupan sehari-hari seperti makan, minum, bicara, sosialisasi, dan rasa percaya diri.

Masalah kesehatan gigi dan mulut di Indonesia dirasakan masih sangat tinggi, hal ini terjadi karena tingkat kesadaran masyarakat untuk menjaga kesehatan gigi dan mulutnya tergolong rendah.Karena masyarakat cendrung meminta perawatan gigi untuk menghilangkan rasa sakit saja. Padahal dokter gigi dan tenaga kesehatan gigi mengharapkan agar pasiennya rutin untuk memeriksakan dirinya, sehingga dapat mengobati dan mencegah komplikasikomplikasi yang berlanjut.

Buruknya kedaan gigi dan mulut pasien bisa dipengaruhi oleh beberapa faktor yakni: (1) pendidikan; (2) ekonomi; (3) sosial; (4) budaya; (5) umur, Sehingga perawatan dilakukan disetiap pasien akan berbedabeda tergantung dari faktor-faktor tersebut. Salah satu faktor yang akan diangkat yakni faktor umur, menurut data internasional dari Bureau of The Census USA, Indonesia memiliki angka peningkatan lansia tertinggi dunia yaitu mencapai 414 persen dari tahun 1990-2015. Sehingga sebagai tenaga kesehatan dalam bidang kesehatan gigi dan mulut harus meningkatkan perawatan dibidang lansia dan, masalah kesehatan gigi yang diderita oleh kebanyakan lansai adalah kehilangan gigi. Jika masalah ini tidak diperbaiki maka akan mengganggu estetik, fonetik, dan mastikasi pasien. Untuk mengatasi masalah tersebut maka pasien tersebut diarahkan untuk melakukan pembuatan gigi tiruan (prostodontia) (Niko Falatehan \& Eddy Kusumah, 2016).

Individu yang mengalami kehilangan gigi apabila dibiarkan akan mengganggu kesehatan gigi dan mulutnya, untuk itu perlu dibuatkan penggantinya berupa gigi tiruan. Namun sering terjadi fungsi yang digantikan tidak maksimal sehingga menimbulkan banyak keluhan. Hal ini dapat berdampak pada produktivitas individu bersangkutan. Pada beberapa kasus dapat mengakibatkan seseorang tidak dapat melakukan kegiatan sehari-hari seperti biasanya, sehingga berdampak pada kualigtas hidupnya. (Chandra dkk, 2014).

\section{METODE PENELITIAN}

Jenis penelitian ini adalah penelitian Observasional Deskriptif dengan pendekatan Cross Sectional untuk mengetahui tingkat kepuasan pemakaian gigi tiruan lepasan terhadap pelayanan di Rumah Sakit Khusus Daerah Gigi dan Mulut Provinsi Sulawesi Selatan. Populasi dalam penelitian ini adalah pengguna gigi tiruan lepasan yang melakukan kunjungan di Rumah Sakit Khusus Daerah Gigi dan Mulut Provinsi Sulawesi Selatan.

Sampel dalam penelitian ini adalah pasien pengguna gigi tiruan lepasan yang berkunjung di ruangan Prostodontia. Penentuan sampel dalam penelitian ini dilakukan dengan menggunakan metode accidental sampling adalah teknik penentuan sampel berdasarkan kebetulan, yaitu siapa saja yang secara kebetulan/ accidentalbertemu dengan peneliti dapat digunakan sebagai sampel. Penelitian ini bertempat di Rumah Sakit Khusus Daerah Gigi dan Mulut Provinsi Sulawesi Selatan. Penelitian ini dilakukan dari bulan Mei-Juni 2019

\section{HASIL DAN PEMBAHASAN}

Penelitian ini dilaksanakan di Rumah Sakit Khusus Daerah Gigi dan Mulut Provinsi 
Sulawesi Selatan, dilakukan pada pasien lama maupun pasien baru yang datang berobat keruangan prosto, dengan jumlah sampel sebanyak 30 responden. Dengan menjawab kuesioner penelitian yang diberikan terhadap tingkat kepuasan pasien berdasarkan lima dimensi kepuasan yaitu: kompetensi teknis (jaminan), efektifitas layanan kesehatan, daya tanggap, tampilan fisiik dan hubungan antar manusia (empati). Diukur berdasarkan rentang Skor Kriteria Kepuasan disajikan dengan menggunakan tabel distribusi frekuensi berikut:

a. Kompetensi Teknis (Jaminan)

Tabel 1 Distribusi Tingkat Kepuasan Pasien Pengguna Gigi Tiruan Lepasan Berdasarkan Dimensi Kompetensi Teknis (Jaminan) di RSKDGM Prov. Sulsel

\begin{tabular}{|c|c|c|}
\hline Tingkat Kepuasan & JumlahPasien & Persentase \\
\hline SangatPuas & 19 & 63.3 \\
\hline Puas & 9 & 30 \\
\hline TidakPuas & 2 & 6.7 \\
\hline SngatTidakPuas & 0 & 0 \\
\hline Total & 30 & 100 \\
\hline
\end{tabular}

Berdasarkan tabel di atas menunjukkan jawaban responden terhadap kualitas pelayanan kesehatan gigi dan mulut untuk variabel KompetensiTeknis (Jaminan) di Rumah Sakit Khusus Daerah Gigi dan Mulut Provinsi Sulawesi Selatan, dari 30

b. Efektifitas Layanan Kesehatan

Tabel 2 Distribusi Tingkat Kepuasan Pasien Pengguna Gigi Tiruan Lepasan Berdasarkan Dimensi Efektifitas Layanan Kesehatan di RSKDGM Prov. Sulsel

\begin{tabular}{|c|c|c|}
\hline Tingkat Kepuasan & Jumlah Pasien & Persentase \\
\hline SangatPuas & 11 & 36.7 \\
\hline Puas & 18 & 60 \\
\hline TidakPuas & 1 & 3.3 \\
\hline SangatTidakPuas & 0 & 0 \\
\hline Total & 30 & 100 \\
\hline
\end{tabular}

Berdasarkan tabel di atas yang menunjukkan jawaban responden terhadap kualitas pelayanan kesehatan gigi dan mulut untuk variabel efektifitas layanan kesehatan di Rumah Sakit Khusus Daerah Gigi dan Mulut Provinsi Sulawesi Selatan, dari 30 responden yang diteliti didapatkan bahwa responden merasa sangat puas dengan persentase $63.3 \%$ sebanyak 19 responden dan puas dengan persentase $36.7 \%$ sebanyak 11 . 
c. Daya Tanggap

Tabel 3 Distribusi Tingkat Kepuasan Pasien Pengguna Gigi Tiruan Lepasan Berdasarkan Dimensi Daya Tanggap di RSKDGM Prov. Sulsel

\begin{tabular}{|c|c|c|}
\hline Tingkat Kepuasan & Jumlah Pasien & Persentase \\
\hline SangatPuas & 16 & 53.3 \\
\hline Puas & 14 & 46.7 \\
\hline TidakPuas & 0 & 0 \\
\hline SangatTidakPuas & 0 & 0 \\
\hline Total & 30 & 100 \\
\hline
\end{tabular}

Berdasarkan tabel diatas yang menunjukkan jawaban responden terhadap kualitas pelayanan kesehatan gigi dan mulut untuk variabel daya tanggap di Rumah Sakit Khusus Daerah Gigi dan Mulut Provinsi Sulawesi Selatan, dari 30

d. Tampilan Fisik responden yang diteliti didapatkan bahwa responden merasa sangat puas dengan persentase $53.3 \%$ sebanyak 16 responden dan puas dengan persentase $46.7 \%$ sebanyak 14 .

Tabel 4 Distribusi Tingkat Kepuasan Pasien Pengguna Gigi Tiruan Berdasarkan Dimensi Tampilan Fisik di RSKDGM Prov. Sulsel.

\begin{tabular}{|c|c|c|}
\hline Tingkat Kepuasan & JumlahPasien & Persentase \\
\hline SangatPuas & 17 & 56.7 \\
\hline Puas & 13 & 43.3 \\
\hline TidakPuas & 0 & 0 \\
\hline SangatTidakPuas & 0 & 0 \\
\hline Total & 30 & 100 \\
\hline
\end{tabular}

Berdasarkan tabel di atas menunjukkan jawaban responden terhadap kualitas pelayanan kesehatan gigi dan mulut untuk variabel tampilan fisik di Rumah Sakit Khusus Daerah Gigi dan Mulut Provinsi
Sulawesi Selatan, dari 30 responden yang diteliti didapatkan bahwa responden merasa sangat puas dengan persentase 56.7 sebanyak 17 responden dan puas dengan persentase $43.3 \%$ sebanyak 13 responden.

e. Hubungan Antar Manusia (Empati)

Tabel 5 distribusi itingkat kepuasan pasien pengguna gigi tiruan lepasan berdasarkan dimensi Hubungan antar manusia (Empati) di RSKDGM Prov. Sulsel

\begin{tabular}{|c|c|c|}
\hline Tingkat Kepuasan & JumlahPasien & Persentase \\
\hline SangatPuas & 24 & 80 \\
\hline Puas & 6 & 20 \\
\hline TidakPuas & 0 & 0 \\
\hline SangatTidakPuas & 0 & 0 \\
\hline Total & 30 & 100 \\
\hline
\end{tabular}


Berdasarkan tabel di atas menujukan kesehatan gigi dan mulut untuk variabel hubungan antar manusia (empati di Rumah Sakit Khusus Daerah Gigi dan Mulut Provinsi Sulawesi Selatan, dari 30 responden yang diteliti didapatkan bahwa responden merasa sangat puas dengan persentase $80 \%$ sebanyak 24 responden dan puas dengan persentase $20 \%$ sebanyak 6 responden.

\section{PEMBAHASAN}

Penilaian (evaluasi) kepuasan perlu diadakan untuk mempertahankan dan menjaga kualitas mutu. Rumah Sakit Khusus Daerah Gigi dan Mulut Provinsi Sulawesi Selatan adalah suatu unit pelaksana fungsional yang berfungsi sebagai pusat pembangunan kesehatan, pusat pembinaan peran serta masyarakat dalam bidang kesehatan dan pusat pelayanan kesehatan tingakat pertama pada suatu masyarakat di daerahnya, tentunya perlu memberikan pelayanan yang baik. Pelayanan yang baik akan menimbulkan perasaan puas dalam diri pasien yang berkunjung dalam pemanfaatan pelayanan kesehatan, khususnya kesehatan gigi dan mulut. Dimensi pengukuran tingkat kepuasan pasien pengguna gigi tiruan lepasan pada penelitian ini dilakukan berdasarkan melihat dari lima dimensi kualitas pelayanan yang menunjang kepuasan pasien yaitu kompetensi teknis (jaminan) efektivitas layanan kesehatan, daya tanggap, tampilan fisik, hubungan antara manusia (empati)

Hasil gambaran tingkat kepuasan yang didapat berdasarkan jawaban kuesioner yang diisi oleh pasien pengguna gigi tiruan lepasan di Rumah Sakit Khusus Daerah Gigi dan Mulut Provinsi Sulawesi
Selatan pada tabel 1 terhadap kompetensi teknis (jaminan), didapatkan hasil bahwa responden merasa Sangat Puas dengan persentase $63.3 \%$ sebanyak 19 responden dan puas dengan persentase $36.7 \%$ sebanyak 11 responden. Penilaian tingkat kepuasan terhadap dimensi kompetensi teknis (Jaminan) dilihat dari beberapa komponen, yaitu Cara petugas kesehatan berkomunikasi saat melakukan pelayanan, Memberikan informasi yang jelas mengenai perawatan yang akan dilakukan. Dalam hal ini, seluruh tenaga kesehatan yang bertugas di Rumah Sakit Khusus Daerah Gigi dan Mulut Provinsi Sulawesi Selatan sangat dapat menjamin atas tindakan yang telah diberikan kepada pasien yang berkunjung.

Hasil gambaran tingkat kepuasan yang didapat berdasarkan jawaban kuesioner yang diisi oleh pasien pengguna gigi tiruan lepasan di Rumah Sakit Khusus Daerah Gigi dan Mulut Provinsi Sulawesi Selatan pada tabel 2 Efektivitas layanan kesehatan, didapatkan hasil bahwa responden merasa Sangat Puas dengan persentase $36.7 \%$ sebanyak 11 responden dan puas dengan persentase $60 \%$ sebanyak 18 responden. Penilaian tingkat kepuasan terhadap dimensi efektifitas layanan kesehatan dilihat dari beberapa komponen, yaitu Tenaga kesehatan melakukan tindakan penanganan dengan baik dan cepat, Di saat melakukan tindakan dokter yang menangani terliatulet, Disaat melakukan tindakan dokter yang menangani terliat ulet, Apakah dokter atau tenaga kesehatan melakukan tindakan dengan tekun. Dalam hal ini, petugas ataupun seluruh tenaga kesehatan yang bertugas di Rumah Sakit Khusus Daerah Gigi dan Mulut Provinsi Sulawesi selatan, melakukan tindakan dengan baik sehingga 
para pasien merasa sangat puas dengan kinerja para tenaga kesehatan.

Hasil gambaran tingkat kepuasan yang didapat berdasarkan jawaban kuesioner yang diisi oleh pasien pengguna gigi tiruan lepasan di Rumah Sakit Khusus Daerah gigi dan Mulut Provinsi Sulawesi Selatan pada tabel 3 terhadap dimensi kualitas pelayanan daya tanggaap didapatkan hasil bahwa responden merasa Sangat Puas dengan persentase $53.3 \%$ sebanyak 16 responden dan puas dengan persentase $46.7 \%$ sebanyak 14 responden. Penilaian tingkat kepuasan terhadap dimensi daya tanggap dilihat dari beberapa komponen, yaitu tanggap dalam menerima keluhan atau komplain dari pasien pengguna gigi tiruan lepasan,lama waktu menunggu, layanan konsultasi yang di berikan dokter sebelum melakukan tindakan,penjelasan mengenai teknik pemakaian dan perawatan gigi tiruan. Dalam hal ini, petugas ataupun seluruh tenaga kesehatan.

\section{KESIMPULAN}

Dari hasil penelitian mengenai tingkat kepuasan pasien pengguna gigi tiruan lepasan terhadap pelayanan kesehatan gigi dan mulut di Rumah Sakit Khusus Daerah Gigi dan Mulut Provinsi Sulsel terdapat lima dimensi variabel yang diteliti yaitu kompetensi teknis (Jaminan), efektifitas layanan kesehatan, daya tanggap, tampilan fisik dan hubungan antar manusia (empati).

\section{SARAN}

Agar para petugas kesehatan mempertahankan semua kualitas pelayanan kesehatan yang telah diterapkan dan kemudian meningkatkan lagi kualitas pelayanan karena semua sangat baik selama peneliti berada di sana.

\section{DAFTAR PUSTAKA}

Andi Ika Anggraini. 2015. Kepuasan pasien terhadap mutu pelayanan kesehatan gigi di poliklinik gigi dan mulut Rumah Sakit Umum Daerah (RSUD) Tenriawaru Kabupaten Bone.Makassar.

Andi TriyantoPujo R. 2017.Desain prangkat analisis mutu pelayanan rumah sakit. Jurnal Simetris

Anna Aulia Rahmah. Gambaran tingkatkepuasan pasien peserta BPJS terhadap pelayanan kesehatan gigi dan mulut di poli gigi puskesmas mochamad Ramadhan Bandung.

Anonim, Gigi Tiruan Sebagian Lepasan Sumber. $\quad$ http://mawar putrijulica.wordpress.com/2009/05/0 4/gigi-tiruan-sebagian-lepasan/. (Diakses 13 Maret 2019)

Anonim, Gigi Tiruan Sebagian Lepasan Sumber. $\quad$ http://mawar putrijulica.wordpress.com/2009/05/0 4/gigi-tiruan-full-lepasan/. (Diakses 13 Maret 2019)

Azwar A.1980. Pengantar administrasi kesehatan. Jakarta: PT. Grafiti Mediko Pers.

Budiharto. 2004. Kemampuan dokter gigi dalam pelayanan. Jurnal Dentistry Indonesia

Chandra Chuanda, Vonny N. S. Wowor, Cristy Mintjelungan. 2014.Gambaran kepuasan pelayanan perawatan gigi tiruan lepasan berbasis akrilik pada masyarakat kelurahan Molas. Manado

Djoko RS. 2008.Sistem pembiyayaan pada pelayanan kesehatan gigi. Jurnal ilmiah dan kedokteran gigi FKG UPDM (B)

Jatuandomi, Paulina N. Gunawan, Krista V. Siagian. 2016.Alasan pemakaian gigi tiruan lepasan pada pasien poliklinik gigi di BLU RSUP Prof. Dr. $R$. D. Kandou Manado.Manado; Jurnal e-GiGi (eG).

Kuntag, Jacobus Rico. 2012. Model Kualitas Pelayanan SERVQUAL (Parasuramaan) et al.

Niken E, Ayubi D. 2008. Hubungan kepuasan pasien bayar dengan minat kunjungan ulang di 
puskesmas wisma jaya Kota Bekasi tahun 2007: Makara Seri Kesehatan Niko Falatehan, Eddy Kusumah.2016. Gambaran tingkat kepuasan estetik dan fenotik pada pemakain gigi tiruan lengkap di Fakultas
Kedokteran Gigi Universitas Trisakti.Cakradonya Dent J Merryani E. Oroh, Sefti Rompas, Linnie Pondang. 2014. Faktor-faktor yang berhubungan dengan tingkat kepuasan pasien rawat inap terhadap pelayanan keperawatan 